\title{
Cytogenetic Impact of Gamma Irradiation and Its Effects on Growth and Yield of Three Soybean Cultivars
}

\author{
Esraa M. El-Azab, Mohamed Soliman, Elham Soliman and Abdelfattah Badr ${ }^{\#}$ \\ Cytogenetics and Molecular Genetics Unit, Botany and Microbiology Department, \\ Faculty of Science, Helwan University, Helwan, Egypt.
}

\begin{abstract}
$\mathbf{H}^{2}$ EALTHY seeds of three soybean cultivars; Crawford, Giza 111 and Giza 35 were irradiated with $\gamma$-irradiationat doses ranging from 100Gy to 600Gy with $100 \mathrm{~Gy}$ interval. The cytogenetic impact of the applied doses was assessed in $M_{1}$ and $M_{2}$ plants, on mitotic activity and chromosomes in root tip meristems and vegetative growth, expressed as shoot and root length and fresh and dry weight of shoot and root as well as leaf area. The low doses of 100 and 200Gy increased mitotic activity, expressed as mitotic index MI and enhanced growth rate. In contrary, higher doses significantly retarded mitotic activity, increased the frequency of chromosomal abnormalities and reduced vegetative growth and yield, expressed as number of pods and seeds weight. The frequency of chromosomal abnormalities was dose dependent and its percentage varied among cultivars. Chromosomal stickiness and noncongression were the most common abnormalities at metaphase and chromosomal bridges and free chromosomes were the most common aberrations at ana-telophase whereas C-metaphase and c lagging chromosomes were only occasionally observed. No abnormalities were reported in the interphase of the $M_{1}$ plants, but in the $M_{2}$ plants, micronuclei and vacuolation of nuclei were frequently observed. The abnormalities reported here are mainly due to a clastogenic action that may have cause breakage and reunion of chromosomes. These findings emphasise the importance of assessing mitotic activity and chromosomes behaviour in plants used for mutation breeding to predict changes invegetative traits and yield of target genotypes.
\end{abstract}

Keywords: Gamma radiation, Soybean, Mitosis, Chromosomes, Growth, Yield.

\section{Introduction}

Soybean (Glycine $\max (\mathrm{L})$ Merr; $2 \mathrm{n}=40$ ) is an annual economically important grain legume crop. It is a commercial crop in many countries as a source of food, feed, as well as use in pharmaceutical and agricultural industry. In addition, soybean is an excellent crop for agriculture cropping systems due to its ability to fix atmospheric $\mathrm{N}_{2}$ symbiotically with sufficient populations of effective rhizobia, a process that leads to increased soil fertility (Keyser \& Li, 1992; Muller et al., 1998 and Tairo \& Ndakidemi, 2013). Mature seeds of soybean contain, approximately $35 \%$ protein, $31 \%$ carbohydrate, $17 \%$ fats, $5 \%$ mineral and $12 \%$ moisture (Messina, 2008). In addition, soybean protein is rich in the valuable amino acid lysine $(5 \%)$ in which most of the cereals is deficient. Moreover, it contains a good quantity of minerals, salts and vitamins. Increased demand of soybean as a multipurpose legume has encouraged using breeding new varieties to increase crop yield and improve the traits of interest (Mudibu et al., 2012; Gobinath et al., 2015 and Kusmiyati et al., 2018).

In plants, breeding is often based on induction of genetic and morphological variations using induced mutations, which has been one of the most efficient methods of breeding in the last five decades. Radiation is an excellent means of stimulating the expression of recessive genes, thus inducing new genetic variation (Song \& Kang, 2003). Since 40 decades ago, gamma rays were found to be more effective than other mutagens in producing viable mutants (Micke, 1984). However, $\gamma$-radiation is ionizing radiation,with low linear energy transfer (LET) that may lead to inherited genetic variation and complicated chromosomal alterations (Sachs et al., 2000). It generates free radicals when interact with a living cell. These radicals may affect all biological activities of the cell (Reisz et al., 2014). High doses can also be

"Corresponding author email: abadr@science.helwan.edu.eg

DOI: 10.21608/ejbo.2018.3656.1173

Edited by: Prof. Dr. Soliman A. Haroun, Faculty of Science, Kafr El-Sheikh University, Kafr El-Sheikh, Egypt.

(C)2018 National Information and Documentation Center (NIDOC) 
detrimental by reducing germination, growth rate, vigour or pollen and ovule fertility as well as yield (Singh, 2005). At low doses, $\gamma$-radiation has been reported to induce both useful and harmful effects on crops, so there is a need to estimate the most beneficial dose for improving specific trait(s) of the crop plant of interest (Badr et al., 2014a,). Low doses of $\gamma$-radiation were used for conventional breeding of agriculturally and economically important legume crops including soybean to increase their genetic variability. Examples include Gobinath et al. (2015), El-Gazzar et al. (2016) and Gaafar et al. (2017).

Cytogenetic analyses are important in assessing genetic impact due to chemical and physical mutagens (Grant, 1999). The most common influence of $\gamma$-irradiation is the chromosomal aberrations induction and affecting the mitotic activity and yield (Melki \& Salami, 2008 and Badr et al., 2014b). The most common chromosomal changes recorded in response to $\gamma$-irradiation were stickiness at metaphase, lagging chromosomes and bridges at anaphase and telophase (Dhanavel et al., 2012). However, the only recoverable chromosomal rearrangements are those that able to produce and replicate DNA molecules and hence can stably inherit to the next generations (Tan et al., 2015). These changes provide the basis for introducing genetic variability in many plant traits (Auger \& Sheridan, 2011).

In the present investigation, $\gamma$-irradiation was applied, at different doses, to explore the possibilities of inducing genetic variability in the three different cultivars of soybean. The induced cytogenetic changes were assessed in two successive generations $\left(\mathrm{M}_{1}\right.$ and $\left.\mathrm{M}_{2}\right)$ following the parent's seeds exposure to different doses of $\gamma$-radiation. The impact on some vegetative parameters and the yield components were also evaluated in $M_{1}$ and $M_{2}$ plants.

\section{Materials and Methods}

\section{Plant materials}

Three soybean cultivars; Giza 111, Giza 35, and Crawford were used in this study. Seeds were obtained from the Legumes and Field Crops Research Department, Agriculture Research Centre (ARC), Giza, Egypt. The three cultivars differ in seed characters and seed weight. Dry seeds of the three soybean cultivars were exposed to six doses of gamma irradiation at the National
Centre for Radiation Research and Technology (NCRRT), Nuclear Research Centre, Inshas, Egypt, using $\mathrm{Co}^{60}$ as a source. The applied doses were 100, 200, 300, 400, 500 and 600Gray (Gy); seeds of control samples were not exposed to irradiation.

\section{Cytological procedures}

For recording the effects of $\gamma$-irradiation on cell division and chromosomes, seeds of $\mathrm{M}_{1}$ and $M_{2}$ soybean cultivars were surface sterilized for two minutes in $1 \%$ sodium hypochlorite followed by several washes in distilled water then grown inside a filter paper moistened with distilled water for seven days. Roots of at least 10 seedlings from each treatment were then fixed in a freshly prepared fixative composed of absolute ethanol and glacial acetic acid (3:1) for $24 \mathrm{~h}$ and kept in 70\% ethanol at $4{ }^{\circ} \mathrm{C}$ until use. The Feulgen's squash technique was used for making permanent preparations as described in Darlington \& La Cour (1976) with some modifications. The Feulgen stained tips were squashed in a drop of $1 \%$ Aceto-Orcein (La Cour, 1941).

The slides were soaked in $70 \%$ ethanol for coverslips separation then, the preparations were fixed by mounting in (D.P.X). Approximately, 6000 cells for each treatment and the control were examined under the $100 \mathrm{X}$ oil objective lens of (JENALAB) light microscope. Mitotic activity was estimated as mitotic index (MI), which is calculated as the ratio of the number of dividing cells to the total number of cells examined. Mitotic stage index (MSI), which is calculated as the ratio of the number of dividing cells at a stage to the total number of dividing cells examined. Chromosomal abnormalities (CA) were scored at all mitotic stages and at interphase and the percentage of cells showing chromosomal abnormalities to the total number of cells at the corresponding stage.

Morphological measurements and yield evaluation

Exposed and control seeds of the three soybean cultivars were grown to maturity under the recommended conditions for growing soybean in field. Plants were irrigated every ten days from sowing until maturity and natural organic fertilizer was applied at the flowering stage. Morphological measurements were made on plants after eight weeks of sowing. The measured traits were length of shoot and root and their fresh and dry weights as well as leaf area and leaves number. At maturity, yield was evaluated by measuring the number 
of pods per plant and weight of 100 seeds. The morphological data were statistically analysed using the one-way analysis of variance (ANOVA) to determine the significance of the variations between treatments. The least significant differences (LSD) were used to determine the level of significance of differences between treatments as compared to their control at 0.05 and 0.01 levels of significance. These statistical methods were performed using the Microsoft office-Excel 2007 and the SPSS version 21 software.

\section{Results}

Impact of $\gamma$-irradiation on mitotic index (MI)

The mitotic activity in root tip cells of the three Glycine max cultivars used in this study was scored as MI values (Table 1). For the $\mathrm{M}_{1}$ plants the Crawford cultivar showed the highest mitotic activity $(\mathrm{MI}=11.17 \pm 0.44)$ and lower MIs (10.45 \pm 0.42$)$ and $(10.61 \pm 0.38)$ were scored for cv. Giza 111 and cv. Giza 35 cultivars, respectively. The low $\gamma$-radiation doses of 100Gy and 200Gy caused a significant increase in the MI values in the three cultivars compared to their controls. High values of $12.25 \pm 0.30$ and $12.27 \pm 0.31$ were scored for cv. Crawford. In contrast, the 500Gy and 600Gy doses significantly decrease the MI values for all cultivars. Lower values of $8.21 \pm 0.24$ and $7.82 \pm 0.19$, respectively were scored for Giza 111. Also, the 300Gy and 400Gy doses showed a highly significant reduction in the MI values for both cv. Giza 35 and cv. Giza 111 while a non-significant reduction was observed for $\mathrm{cv}$. Crawford.

Interestingly, the mitotic activities in the $\mathrm{M}_{2}$ plants displayed similar pattern to $\mathrm{M}_{1}$ plants (Table 2). The cv. Crawford scored the highest MI value of $11.17 \pm 0.48$, while cv. Giza 111 scored the lowest value of MI $(10.21 \pm 0.43)$. The effect of applied $\gamma$-radiation was doses dependent regardless of the cultivar type. Generally, the low doses of 100Gy and 200Gy significantly enhanced mitotic activity for all cultivars; MI reached to $12.76 \pm 0.32,12.97 \pm 0.49$ and $12.37 \pm 0.47$ for cv. Crawford, cv. Giza 35 and cv. Giza 111, respectively at the dose of 200Gy.On other hand, the 400Gy and 500Gy showed a significant to highly significant reductionsin MI in the three cultivars. While the $300 \mathrm{~Gy}$ dose shows a nonsignificant reduction in all cultivars.

\section{Frequency and types of chromosomal abnormalities}

All doses of $\gamma$-radiation induced highly significant elevations in the proportion of cells showing chromosomal abnormalities. This elevation was proportional to an increment of $\gamma$-radiation dose in both $M_{1}$ and $M_{2}$ generations. In $\mathrm{M}_{1}$ plants, both cv. Giza 111 and cv. Giza 35 showed high percentage of chromosomal abnormalities at the dose of 600Gy (23.68 \pm 1.93 and $22.91 \pm 2.93$ ) respectively, compared to $16.78 \pm 2.49$ in cv. Crawford at the same dose. Meanwhile, the lower doses of 100Gy and 200Gy induced abnormalities but at lower levels. In cv. Giza 35, much lower proportions of abnormalities $(4.31 \pm 0.64)$ were recorded compared to the other cultivars at a dose of 100Gy (Table1).

Interestingly, in $\mathrm{M}_{1}$ plants no chromosomal abnormalities were observed for the cells at interphase and prophase stages. The highest proportional of chromosomal abnormalities was observed at metaphase and ana-telophase in all cultivars (Table 1). Non-congression and stickiness were the most predominant types of abnormalities at metaphase stage. While Chromosome bridge and free chromosome were the most common abnormalities observed for all cultivars at ana-telophase stage. In $\mathrm{M}_{2}$ plants the highest significant percent of chromosomal abnormalities was observed for Crawford cultivar (45.20 \pm 1.66$)$ at $\gamma$-irradiation dose of 400Gy. While the lower value of $(7.69 \pm 0.66)$ was observed for Giza 111 at 100 Gy of $\gamma$-irradiation dose.

In contrast to the $M_{1}$ plants, chromosomal abnormalities were observed for the cells at interphase stage of $\mathrm{M}_{2}$ plants however to low extent. All $\gamma$-irradiation doses showed greatly varied proportional values of vacuolated nuclei, irregular shaped nucleus and micronucleus at interphase stage for the three cultivars. Like $\mathrm{M}_{1}$ plants the highest proportional of chromosomal abnormalities for $\mathrm{M}_{2}$ plants was observed at metaphase, anaphase and telophase in all cultivars. Non-congression and stickiness were the most predominant types of abnormalities at metaphase stage. While chromosome bridge and free chromosome were the most common abnormalities observed for all cultivars at anaphase and telophase stage in addition to lagging chromosomes (Table 2 and Fig. 1). 


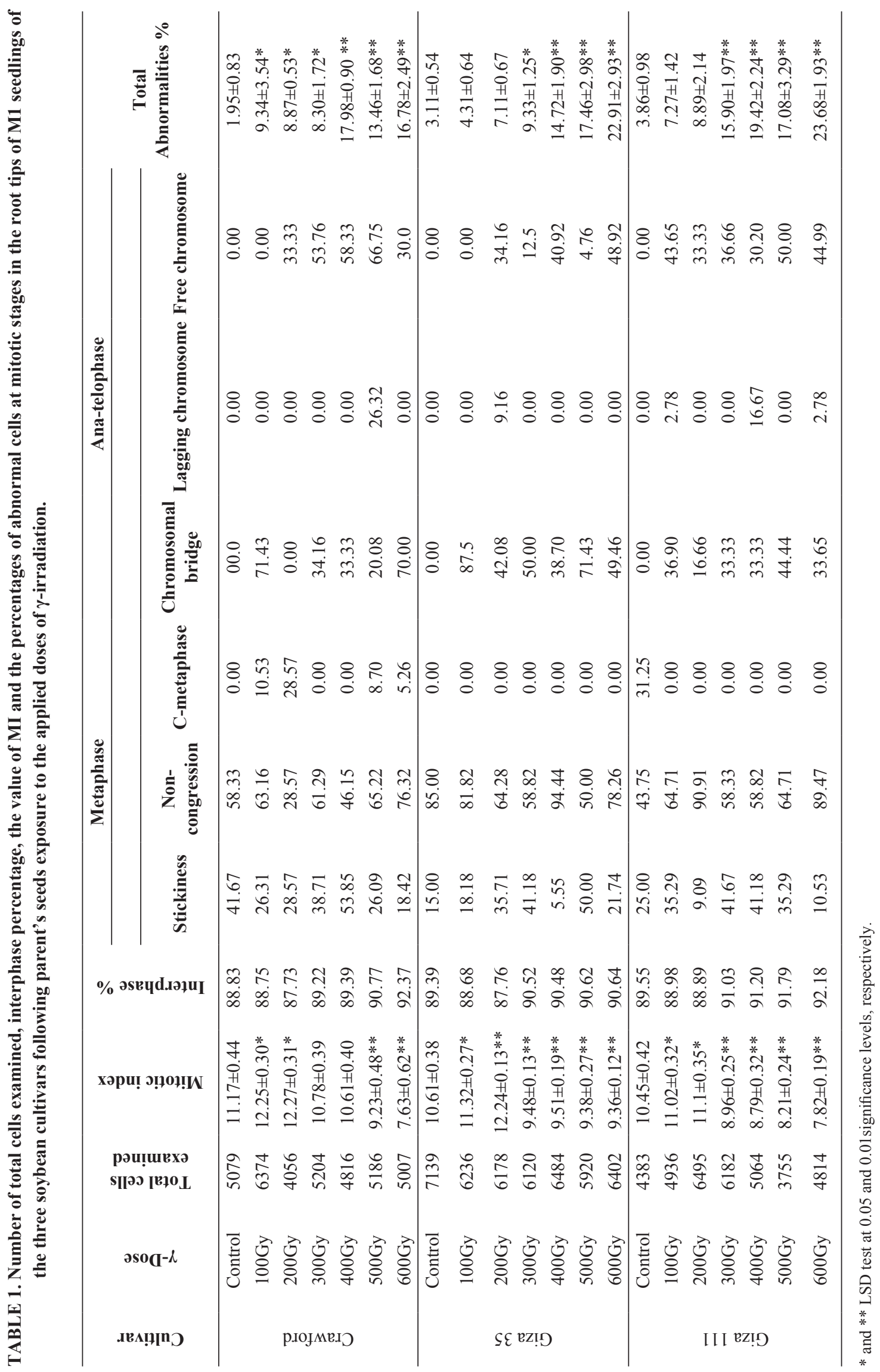

Egypt. J. Bot. 58, No.3 (2018) 


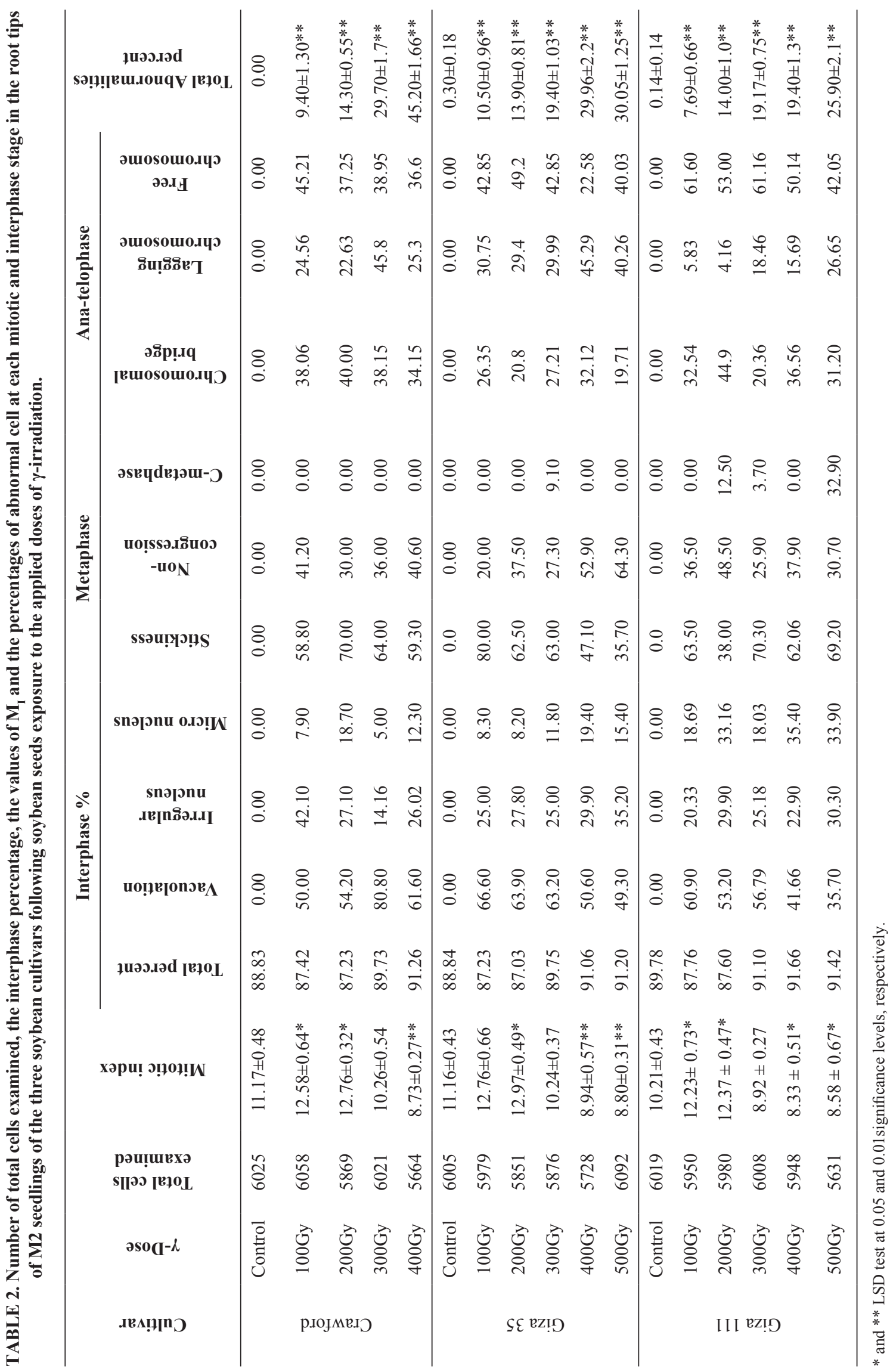



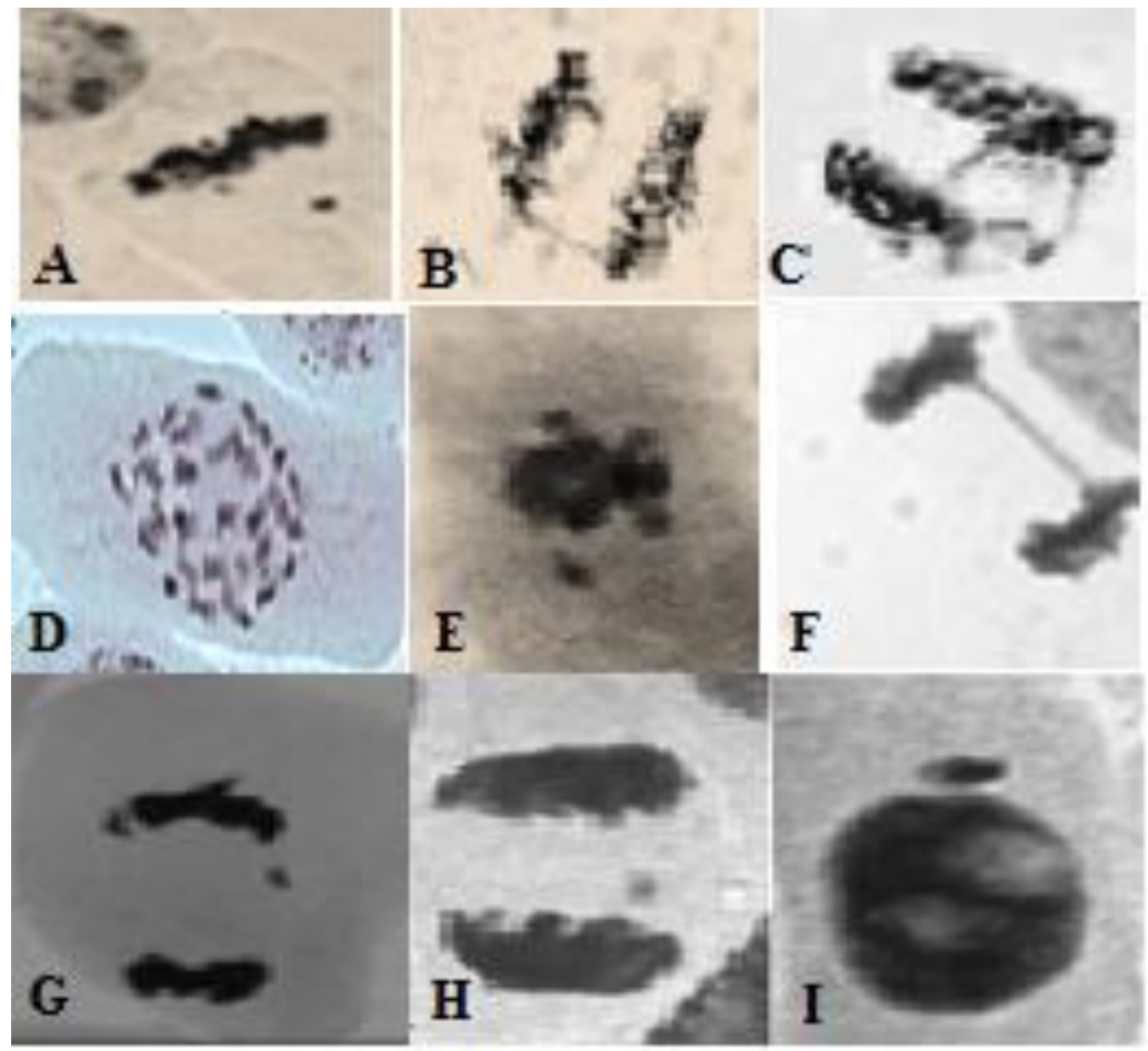

Fig. 1. Types of chromosomal abnormalities in the root tips of M1 seedlings of the three soybean cultivars following seeds exposure to the applied $\gamma$-irradiation doses. (A) Non congression chromosome at sticky metaphase induced by 200Gy in M1 seedlings of cv. Giza 111. (B) Chromatid bridge at anaphase induced by 100Gy in M1 seedlings of cv. Giza 111. (C) Two chromatid bridges at telophase induced by 600Gy in M1 seedlings of cv. Giza 35. (D) C- metaphase induced by 500 Gy in M2 seedlings of cv. Giza 111. (E) Un-oriented chromosome at metaphase induced by $500 \mathrm{~Gy}$ in $\mathrm{M} 2$ seedlings of cv. Giza 35. (F) Chromatid bridge at anaphase induced by $400 \mathrm{~Gy}$ in M2 seedlings of cv. Giza 35. (G) Free chromosome and lagging chromosome at telophase induced by $400 \mathrm{~Gy}$ in $\mathrm{M} 2$ seedlings of cv. Giza 35. (H) Lagging chromosome at telophase induced by 300Gy in M2 seedlings of cv. Crawford. (I) Micro-nucleus at interphase induced by 200Gy in M2 seedlings of cv. Giza 111.

\section{The impact of $\gamma$-radiation on growth and yield}

All vegetative growth parameters measured, in the current study, clearly indicate that the low doses of 100Gy and 200Gy were highly significantly effective in enhancing vegetative growth of the shoot and root lengths, fresh and dry weights also, caused a similar influence on leaf measurements at early stages of growth of 8 weeks after sowing. In contrary, all high doses of $300 \mathrm{~Gy}$ to $500 \mathrm{~Gy}$ were highly significantly reducing all growth parameter measurements. Figures illustrating variations in shoot and root length, dry weight, leaf number per plant and leaf area of $M_{1}$ plants of the three soybean cultivars following parent seed exposure to different doses of $\gamma$-radiation are shown in Fig. 2 (A-H), respectively. Moreover, an increased sensitivity of $\mathrm{cv}$. Crawford to the high dose of 500Gy was noticed and causes a detrimental effect on its growth leading to complete death of the $\mathrm{M}_{2}$ plants. The same morphological observations at the low doses of 100Gy and 200 Gy and high doses of 300 Gy to 500Gy were generally maintained in $\mathrm{M}_{2}$ plants (data not shown). 
As observed for the vegetative traits measurements, the low doses of $100 \mathrm{~Gy}$ and 200Gy resulted in a highly significant increase in the measured yield parameters, i.e., the number of pods per plant, number of seeds per plant and weight of 100 seeds in the three soybean cultivars.

A

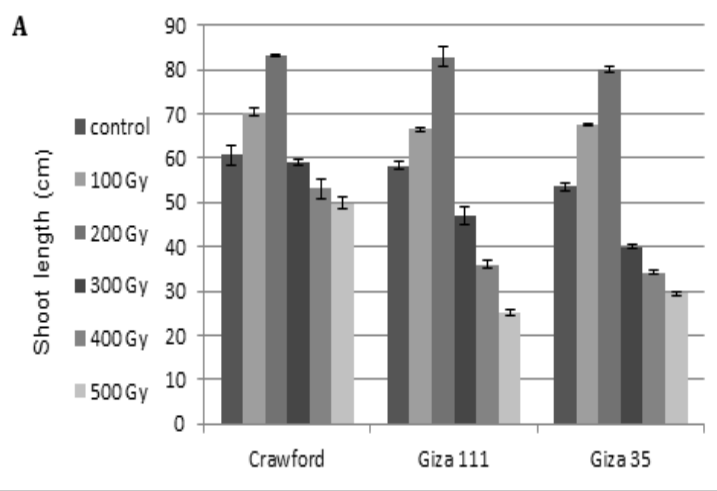

C
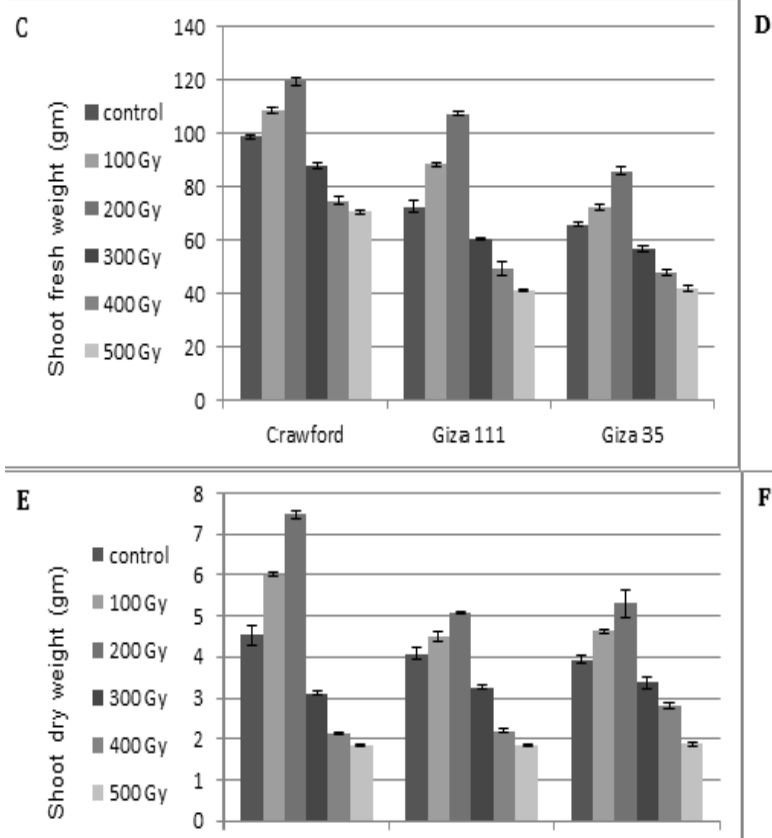

Crawford

Giza 111

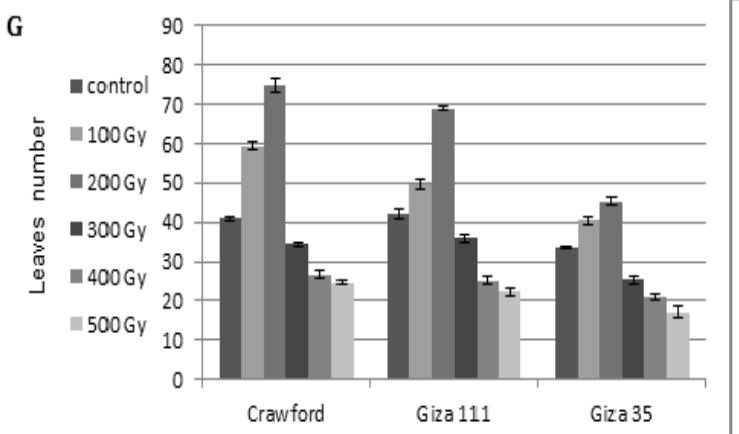

D

H
In contrary, a significant retardation in all yield parameters that were measured was observed following exposure to 300Gy, 400Gy and 500Gy doses in both $\mathrm{M}_{1}$ (Fig. $3 \mathrm{~A}-\mathrm{C}$ ) and $\mathrm{M}_{2}$ plants (data not shown).

\section{B}
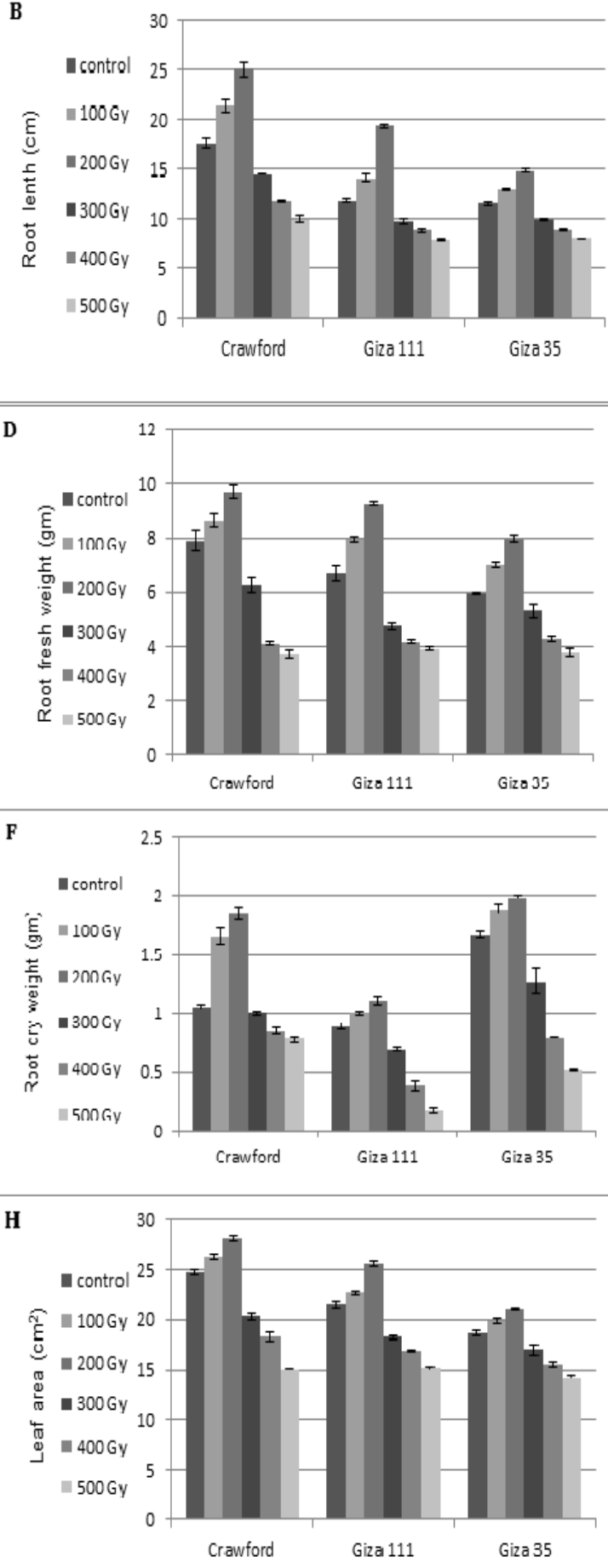

Fig. 2. Histograms illustrating changes in some vegetative parameters of M1 plants of three soybean cultivars following seed exposure to different doses of $\gamma$-radiation. (A) Shoot length, (B) Root length, (C) Shoot fresh weight, (D) Root fresh weight, (E) Shoot dry weight, (F) Root dry weight, (G) Ieaves number/plant, (H) Leaf area. 

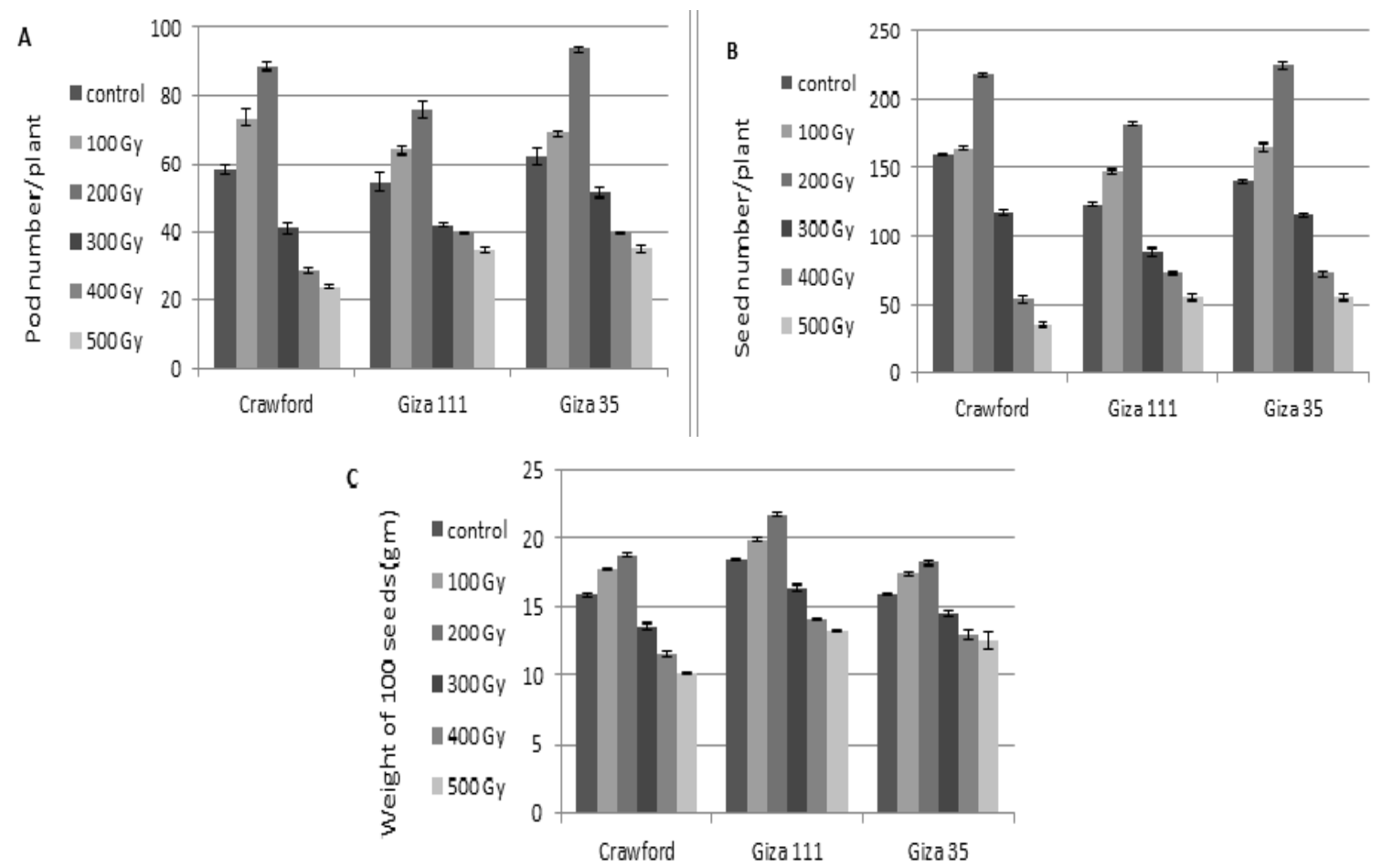

Fig. 3. Histograms illustrating changes in some yield parameters of M1 plants of three soybean cultivars following seed exposure to different doses of $\gamma$-radiation. (A) Pod number/plant, (B) Seed number/plant, (C) weight of 100 seeds.

\section{Discussion}

The positive and negative consequences of $\gamma$-radiation were evaluated by comparison to nonirradiated plants for two successive generation of soybean. Mitotic index was used as an indicator to describe the cell activity and proliferation (Simon et al., 2014); it was significantly increased, in both $M_{1}$ and $M_{2}$, in the three soybean cultivars when the parent'sseeds were exposed to low doses of 100Gy and $200 \mathrm{~Gy}$ of $\gamma$-radiation. In the contrary, higher doses of 500Gy and 600Gy negatively affect the MI values in all cultivars. Similar inhibitory effect on the mitotic activity following exposures to high doses of $\gamma$-radiation was observed in $M_{1}$ and $M_{2}$ plants of cowpea (Badr et al., 2014b) and faba bean (El-Gazzar et al., 2016). Low doses of gamma irradiation could stimulate the production of few reactive oxygen species (ROS) (Smith et al., 2012) that mediate the acceleration of cell cycle entry to G0/G1 leading to a positive effect on the plant cell cycle machinery (Fehér et al., 2008).

Although, normal cell cycle segregation was displayed in the $M_{1}$ plants; a significant increase in the mitotic chromosomal abnormalities was observed following exposure to $\gamma$-irradiations, most likely is a result of increased sensitivity of chromatin in mitotic cells to radiation than the dispersed chromatin of interphase cells (Stobbe et al., 2009). However, in $M_{2}$ plants, considerable proportions of interphase cells showed nuclear abnormalities. The level of chromosomal rearrangements observed was proportional to the $\gamma$-irradiations dose. The chromosomal abnormalities were stickiness and non-congression at metaphase and free chromosome, chromosome laggards and bridges at ana-telophase stages. Similar observations were observed in other legumes following exposure to $\gamma$-irradiations such as cowpea (Dhanavel et al., 2012 and Badr et al., 2014b) and faba bean (El-Gazzar et al., 2016 and Nurmansyah et al., 2017). High doses of ionized radiation induce DNA double-strand breaks which trigger genetic instability if persisted without repair and lead to gross chromosomal rearrangements to alleviate the destabilizing effect of the radiation. This allows cell survival with a delay in the passage of cells through the G2/M phase cellcycle checkpoint (De Veylder et al., 2003 and De Simone et al., 2017). Low doses of $\gamma$-irradiations, on the other hand stimulate the production of few reactive oxygen species (ROS) (Smith et al., 2012) that mediate the acceleration of cell cycle entry to $\mathrm{G} 0 / \mathrm{G} 1$ leading to enhanced plant cell cycle machinery (Fehér et al., 2008). 
Chromosome stickiness might be due to changes in specific non-histone proteins, histone proteins and DNA breaks induced during chromosome condensation (Gaulden, 1987 and Piskadlo et al., 2017). Chromosome noncongression represent an expelled chromosomes at metaphase due to improper balance between opposing pulling action of kinetochore and/ or pushing ejection forces of the poles along chromosome arms that fails to reach an equilibrium near the spindle equator (Maiato et al., 2017). A mitosis-specific and R loop-driven ATR pathway promotes faithful chromosome segregation, it stimulates Aurora B through Chk1, preventing formation of lagging chromosomes (Kabeche et al., 2018). The free and the lagging chromosomes at ana-telophase might be formed due to the failure of spindle fibres to push the respective chromosomes to the poles due to failure in the ATR pathway due to exposure to $\gamma$-irradiations.

The behavior of laggards is characteristic in that they generally lead to micronuclei formation (Badr, 1987 and Kumar \& Rai, 2006). At telophase the segregated sister chromatids de-condense and the nuclear envelope re-forms around them, the same happens for the spatially expelled free chromosomes or chromosome fragments leading to the formation of the micronucleus (Potapova \& Gorbsky, 2017). Micronuclei also arise if laggards or non-oriented free chromosomes that fail to reach the poles in time to be in the main telophase nucleus (Utsunomiya et al., 2002). Micronuclei derived from a whole chromosome, due to lagging, have a higher probability to survive and undergo condensation in synchrony with the main nuclei than micronuclei derived from a chromosome fragment (Gustavino et al., 1987). Micronuclei often serve as a marker of chromosomal instability, so it used as a tool to assess the genotoxicity of various environmental chemicals and other hazardous substances. However, Luzhna et al. (2013) proposed that micronucleus formation may precisely reflect individual sensitivity due to single gene polymorphisms.

Chromosome bridges were commonly observed during anaphase and telophase, in $\mathrm{M}_{1}$ and $\mathrm{M}_{2}$ plants, indicating a clastogenic effect caused by breakage and fusion of chromatids or sub-chromatids (Badr, 1987 and Grant, 1999) indicating stable structural aberrations that are transmissible such as inversions, translocations and some small deletions. Bridges reported here like bridges produced by other mutagenic agents might have arisen through breaks followed by reunion of chromosomes (Kumar et al., 2003 and Kumar \& Rai, 2006) or due to stickiness of chromosome at metaphase and their failure to separate at anaphase (Grant, 1999 and Dhanavel et al., 2012). Most likely, the $\gamma$-irradiation induces chromosomal breaks in two chromosomes that tend to reunite forming a chromosomal connection between the two poles (Pampalona et al., 2016).

Low radiation levels of $100 \mathrm{~Gy}$ and $200 \mathrm{~Gy}$ highly promoted plant growth and yield of $\mathrm{M}_{1}$ plants that constantly maintained in the $\mathrm{M}_{2}$ plants. While high levels of $300 \mathrm{~Gy}$ to $500 \mathrm{~Gy}$ of $\gamma$-irradiation negatively affected both plant growth and yield causing deleterious damage, particularly on the $\mathrm{M}_{2}$ generation of $\mathrm{cv}$. Crawford, which failed to grow to flowering and hence seed production. The positive effect on vegetative and yield in plants grown from seeds exposed to 100Gy and 200Gy is associated with a similar positive effect on mitotic activity in the root meristems. Meanwhile, the reduction in growth and yield at high doses of $\gamma$-irradiation are associated with reduced mitotic activity in the three soybean cultivars compared to their controls. Similar correlation, i.e "low dosehigh growth and yield" was also observed in other legumes including cowpea (Badr et al., 2014a; b), lens (Kumar et al., 2003), common bean (ElGazzar et al., 2016) and in soybean (Gobinath et al., 2015 and Gaafar et al., 2017).

The enhanced effect of low doses of irradiation may be the result of a"radiation hormesis" due to transfer of energy to cellular atoms practically, hydrogen $(\mathrm{H})$, carbon $(\mathrm{C})$, oxygen $(\mathrm{O})$, nitrogen $(\mathrm{N})$ and phosphorus (P) that may lead to stimulating effect on the physiological reactions in living cells including, cell division and growth (Yadav, 2016). On other hand, higher doses of $\gamma$-irradiation impair physiological processes leading to cytotoxic effects. These effects may be produced as a response to elevated levels of oxidative stress that exceeds the capacity of cellular antioxidant defences to remove stress (Taguchi \& Kojima, 2005). In association, DNA damage repair mechanisms may alleviate the encountered damage and enable the plants to survive (Datta et al., 2011 and De Simone et al., 2017).

The measured yield parameters, i.e., number of pods per plant and the 100 -seed weight, increased 
following exposure to the 100Gy dose. While the 300Gy, 400Gy and 500Gy doses significantly reduced all yield parameter in the three used cultivars in $M_{1}$ and $M_{2}$ plants. However, a deleterious effect was observed for the Crawford cultivar at the 500Gy dose of $\gamma$-irradiation in $\mathrm{M}_{2}$ plants. This finding is proportionally correlated with the measurements of vegetative parameters. Improvement of agronomic traits by using $\gamma$-irradiation has been reported in other legumes. In cowpea, low $\gamma$-irradiation doses of 100 and 200Gy enhanced yield; interestingly, this improvement was cultivar dependent (Badr et al., 2014b). Similar findings were found in faba bean (El-Gazzar et al., 2016). Low doses of $\gamma$-radiation were also used to increase the genetic variability in soybean (Gobinath et al., 2015) and cowpea (Badr et al., 2014a; b and Gaafar et al., 2017).

\section{Conclusions and Recommendations}

Low doses of $\gamma$-irradiation (100Gy and 200Gy) enhanced mitotic activity in the root tip meristems of three soybean cultivars (Crawford, Giza 35, and Giza 111) that has been reflected as increased vegetative growth and improved yield. However, high doses (300Gy to 600Gy) reduced $\mathrm{M}_{\mathrm{I}}$ vegetative growth and yield; the later dose was lethal to cv. Crawford. The frequency of chromosomal abnormalities at mitosis was dose dependent and its percentage varied among cultivars, but nuclear abnormalities were only observed in the $\mathrm{M}_{2}$ generation plants. The selection of individual plants in the $\mathrm{M}_{2}$ generation can be studied to observe the spectrum of variation for traits and observation of mutants, synchronous maturation in $\mathrm{M}_{3}$ and $\mathrm{M}_{4}$ generations that can be used as donors for restructuring soybean genotypes. When transmitted to the next generations, mutations could boost adaptive genome evolution and generate new beneficial traits.

\section{References}

Auger, D.L. and Sheridan, W.F. (2011) Plant chromosomal deletions, insertions and rearrangements. In: "Plant Cytogenetics: Genome Structure and Chromosome Function", Bass, H.W. and Birchler, J.A. (Ed.), pp. 3-36. Plant Genetics and Genomics: Crops and Models Series Vol. 4. Springer Verlag.

Badr, A. (1987) Effect of the S-triazine herbicide turbutryn on mitosis, chromosomes and nucleic acids in root tips of Vicia faba. Cytologia, 51, 571-577.

Badr, A., Sayed-Ahmed, H.I., Hamouda, M., Halawa, M. and Elhiti, M. (2014a) Variation in growth, yield and molecular genetic diversity of $\mathrm{M}_{2}$ plants of cowpea following exposure to gamma radiation. Life Science Journal, 11(8), 10-19.

Badr, A., El-Shazly, H.H. and Halawa, M. (2014b) Cytological effects of gamma radiation and its impact on growth and yield of $\mathrm{M}_{1}$ and $\mathrm{M}_{2}$ Plants of Cowpea Cultivars. Cytologia, 79(2), 195-206.

Darlington, C.D. and La Cour, L.F. (1976) "The Handling of Chromosomes", $6^{\text {th }}$ ed. George Allen and Unwin Ltd., London.

Datta, S.K., Chakrabarty, D., Verma, A.K. and Banerji, B.K. (2011) Gamma ray induced chromosomal aberrations and enzyme related defence mechanism in Allium cepa L. Caryologia, 64, 388-397.

De Simone, A., Hubbard, R., de la Torre, N.V., Velappan, Y., Wilson, M., Considine, M.J. and Foyer, C.H. (2017) Redox changes during the cell cycle in the embryonic root meristem of Arabidopsis thaliana. Antioxidants \& Redox Signaling, 27(18), 1505-1519.

De Veylder, L., Loubès, J. and Inzé, D. (2003) Plant cell cycle transitions. Current Opinion. in Plant Biology, 6, 536-543.

Dhanavel, D., Gnanamurthy, S. and Girija, M. (2012) Effect of gamma rays on induced chromosomal variation in cowpea Vigna unguiculata (L.) Walp. International Journal of Current. Science, 12, 245250.

El-Gazzar, N., Mekki, L., Heneidak, S. and Badr, A. (2016) ISSR markers associated with effects of gamma irradiation on growth and seed yield of $\mathrm{M}_{2}$ plants of faba bean (Vicia faba L.). The Arab Journal of Sciences \& Research Publishing, 2(2), 75-89; Article no: AJSRP/ N22116.

Fehér, A., Ötvös, K., Pasternak, T.P. and Szandtner, A.P. (2008) The involvement of reactive oxygen species (ROS) in the cell cycle activation (G0-to-G1) transition of plant cells. Plant Signaling \& Behavior, 3(10), 823-826.

Gaafar, R.M., Elshanshory, A.R., Hamouda, M. and 
Diab, R. (2017) Effect of various doses of gamma radiation on phenotypic and molecular characteristics of two Egyptian soybean varieties. Egyptian Journal of. Botany, 57, 199-216

Gaulden, M.E. (1987) Hypothesis: Some mutagens directly alter specific chromosomal proteins to produce chromosome stickiness. Mutagenesis, 2, 357-365.

Gobinath, P. and Pavadai, P. (2015) Effect of gamma rays on morphology, growth, yield and biochemical analysis in soybean (Glycine max (L.) Merr.). World Scientific News, 23, 1-12

Grant, W.F. (1999) Higher plant assays for the detection of chromosomal aberrations and gene mutations - A brief historical background on their use for screening and monitoring environmental chemicals. Mutation Research, 426, 107-112.

Gustavino, B., Vitagliano, E., Sottili, A. and Rizzoni, A. (1987) A comparison between short-term evolution of micronuclei induced by X-rays and colchicine in root tips of Vicia faba. Mutation Research/ Fundamental and Molecular Mechanisms of Mutagenesis, 192, 109-119.

Kabeche, L., Nguyen, H.D., Buisson, R. and Zou, L. (2018) A mitosis-specific and R loop-driven ATR pathway promotes faithful chromosome segregation. Science, 359(6371), 108-114.

Keyser, H.H. and Li, F. (1992) Potential for increasing biological nitrogen fixation in soybean. Plant and Soil, 141, 119-135.

Kumar, G. and Rai, P. (2006) Partial genome elimination through micronuclei in soybean (Glycine max). National Academy Science Letter. 29, 417-421.

Kumar, G., Kesarwani, S. and Sharma, V. (2003) Clastogenic effect of individual and combined treatment of Gamma rays and EMS in Lens culinary. Journal of Cytology and Genetics, 4, 149-154.

Kusmiyati, F., SutarnoSas, M.G.A. and Herwibawa, B. (2018) Mutagenic effects of gamma rays on soybean (Glycine max L.) germination and seedlings. IOP Conf. Series: Earth and Environmental Science, 102, 012059 .

La Cour, L.F. (1941) Acetic-orcein. Stain Technology, 16, 169-74.
Luzhna, L., Kathiria, P. and Kovalchuk, O. (2013) Micronuclei in genotoxicity assessment: From genetics to epigenetics and beyond. Frontiers of Genetics, 4, 131.

Maiato, H., Gomes, A.M., Sousa, F. and Barisic, M. (2017) Mechanisms of chromosome congressionduring mitosis. Biology, 6(1), 13.

Melki, M. and Salami, D. (2008) Studies the effects of low dose of gamma rays on the behaviour of Chickpea under various conditions. Pakistan J Biological Science, 11, 2326-2330.

Messina, M. (2008) Investigating the optimal soy protein and isoflavone intakes for women: A perspective. Women's Health, 4, 337-356.

Micke, A. (1984) Mutation breeding in grain legumes. Plant \& Soil, 82, 337-358.

Mudibu, J., Nkongolo, K.K.C., Kalonji-Mbuyi, A. and Kizungu, R.V. (2012) Effect of gamma irradiation on morpho-agronomic characteristics of soybeans (Glycine max L.). American Journal of Plant Science, 3, 331-337.

Muller, U., Weber, W., Hoffmann, A., Franke, S., Lange, R. and Vieths, S. (1998) Commercial soybean lecithins: A source of hidden allergens? ZeitschriftLebensmittelUntersuchung und-Forschung A, 207, 341-351.

Nurmansyah, S.S., Alghamdi, H.M. and Farooq, M. (2017) Morphological and chromosomal abnormalities in gamma radiation-induced mutagenized faba bean genotypes. International Journal of Radiation Biology, 94(2), 174-185.

Pampalona, J., Roscioli, E., Silkworth, W.T., Bowden, B., Genescà, A., Tusell, L. and Cimini, D. (2016) Chromosome bridges maintain kinetochoremicrotubule attachment throughout mitosis and rarely break during anaphase. PLOS ONE, 11(1), e0147420.

Piskadlo, E., Tavares, A. and Oliveira, R.A. (2017) Metaphase chromosome structure is dynamically maintained by condensin I-directed DNA (de) catenation. eLife, 6, e26120.

Potapova, T. and Gorbsky, G.J. (2017) The Consequences of chromosome segregation errors in mitosis and meiosis. Biology, 6(1), 12. 
Reisz, J.A., Bansal, N., Qian, J., Zhao, W. and Furdui, C.M. (2014) Effects of ionizing radiation on biological molecules - Mechanisms of damage and emerging methods of detection. Antioxidants \& Redox Signaling, 21(2), 260-292.

Sachs, R.K., Hiatky, L.R. and Trask, B.J. (2000) Radiation-produced chromosome aberrations. Trends in Genetics, 16,143-146.

Simon, S., Angharad, J. and James, A.H.M. (2014) The plant cell cycle in context. Journal of Experimental Botany. 65(10), 2557-2562.

Singh, B.D. (2005) Mutations in crop improvement. In: "Plant Breeding, Principles, and Methods", Singh, B.D. (Ed.), pp. 698-731. Kalyani Publishers, Ludhiana.

Smith, J.T., Willey, N.J. and Hancock, J.T. (2012) Low dose ionizing radiation produces too few reactive oxygen species to directly affect antioxidant concentrations in cells. Biology Letters, 8(4), 594-597.

Song, H.S. and Kang, S.Y. (2003) Application of natural variation and induced mutation in breeding and functional genomics: Papers for International Symposium; Status and Future of Plant Mutation Breeding. Korean J. Breed Sci. 35(1), 24.

Stobbe, C.C., Park, S.J. and Chapman, J.D. (2009) The radiation hypersensitivity of cells at mitosis,
International Journal of Radiation Biology, 78(12), 1149-1157.

Taguchi, M. and Kojima, T. (2005) Yield of OH radicals in water under high-density energy deposition by heavy-ion irradiation. Radiation Research, 163, 55-461.

Tairo, E.V. and Ndakidemi, P.A. (2013) Yields and economic benefits of soybean (Glycine $\max$ L.) as affected by Bradyrhizobium japonicum inoculation and phosphorus supplementation. American Journal of Research Communication, 1, 159-172.

Tan, E.H., Henry, I.M., Ravi, M., Bradnam, K.R., Mandakova, T., Marimuthu, M.P. and Chan, S.W. (2015) Catastrophic chromosomal restructuring during genome elimination in plants. eLife, $\mathbf{4}$, e06516.

Utsunomiya, K.S., Bione, N.C.P. and Pagliarini, M.S. (2002) How many different kinds of abnormalities could be found in unique endogamous maize plant? Cytologia, 67, 169-176.

Yadav, V. (2016) Effect of gamma radiation on various growth parameters and biomass of Canscora decurrens Dalz. International Journal of Herbal Medicine, 4(5), 109-115.

\section{التأثيرات الوراثية الخلوية لأثشعة جاما وتأثير ها على نمو وانتاجية ثلاثة أصناف من فول الصويا

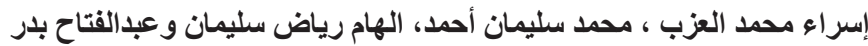

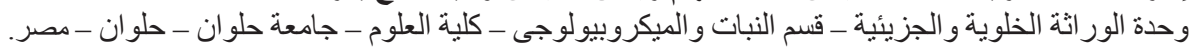

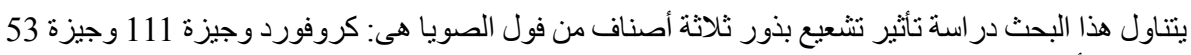

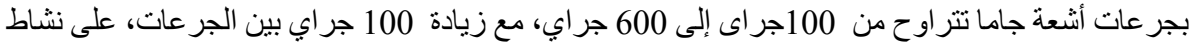

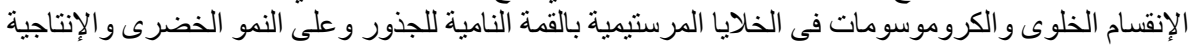

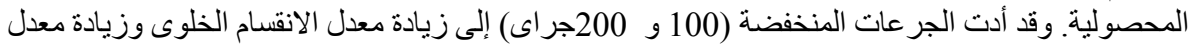

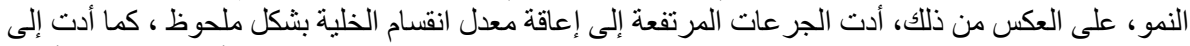

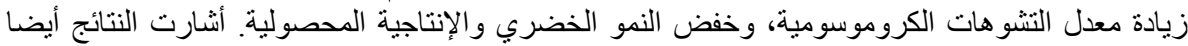

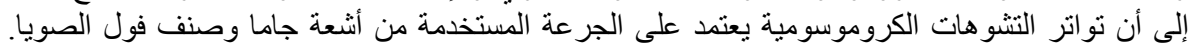

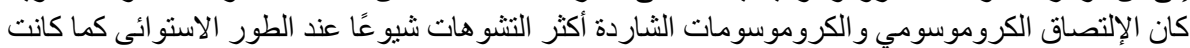

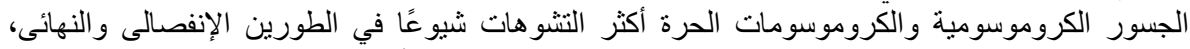

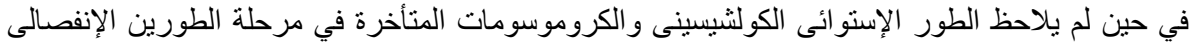

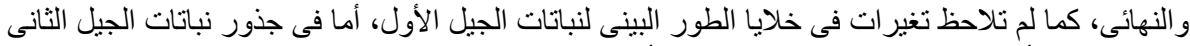

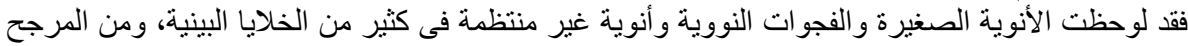

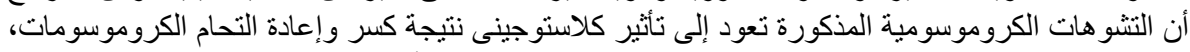

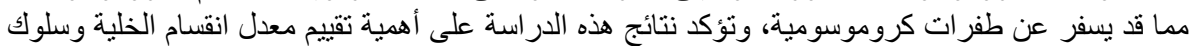

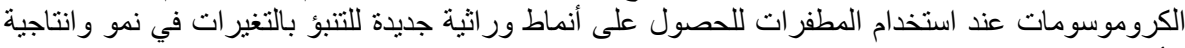
الأنماط الور اثية المستهدفة منداث 